\title{
Percepción de la contaminación visual por paneles publicitarios y afiches: una revisión jurídica
}

\author{
Perception of visual contamination by panels publicity \\ and posters: a legal review
}

\author{
Karina Melissa Brañez Meza ${ }^{1 *}$, Duany Cisneros Solis Pereira ', Andrea Vasquez Huaynate ${ }^{1}$ \\ y Emma C. Jaramillo Cabrera ${ }^{1}$ \\ Facultad de Derecho, Universidad Continental, Huancayo, Perú
}

\section{RESUMEN}

El objetivo de la investigación es percibir la contaminación visual producida por los paneles publicitarios y afiches, desde el aspecto jurídico. Se utilizó un diseño descriptivo, para la recolección de datos se aplicó una encuesta a 80 personas que transitaban cerca a los afiches y paneles publicitarios indagando acerca de su percepción respecto a la contaminación visual, tales como los efectos y consecuencias y la regulación de ésta. Entre los resultados se obtuvo que, el $70 \%$ de los encuestados, no conocían la contaminación visual, pese a estar directamente afectados, el $80 \%$ señalo que los paneles publicitarios y afiches les genero irritación a la vista, el $20 \%$ estrés, $90 \%$ señalo que nunca realizo alguna denuncia o queja, y el $60 \%$ de los ciudadanos no saben cómo reaccionar frente a esta problemática, sin embargo no fue estadísticamente significativa. Respecto al conocimiento del tema de la contaminación visual, $30 \%$ de los encuestados demostró su conocimiento respecto a esta materia. En conclusión, los ciudadanos no perciben los efectos y causas de la contaminación visual, por lo que se requiere de una adecuada concientización para no alterar el paisaje o desequilibrio de la imagen urbana y sobre todo se regule y fiscalice correctamente la contaminación visual, además de sancionar a los responsables conforme a ley.

Palabras Clave: Estética paisaística, publicidad, paneles publicitarios, afiches.

\begin{abstract}
The objective of the research is to perceive the visual contamination produced by the advertising panels and posters, from the legal aspect. A descriptive design was used, for the collection of data a survey was applied to 80 people who traveled near the posters and advertising panels inquiring about their perception regarding visual contamination, such as the effects and consequences and the regulation of it. Among the results was that, $70 \%$ of respondents, did not know the visual pollution, despite being directly affected, $80 \%$ indicated that the advertising panels and posters generate irritation in view, $20 \%$ stress, $90 \%$ I point out that I never made any denunciation or complaint, and $60 \%$ of citizens do not know how to react to this problem, however it was not statistically significant. Regarding knowledge of the topic of visual pollution, $30 \%$ of the respondents demonstrated their knowledge regarding this matter. In conclusion, citizens do not perceive the effects and causes of visual pollution, which is why an adequate awareness is required so as not to alter the landscape or imbalance of the urban image and, above all, to regulate visual pollution.
\end{abstract}

Keywords: Landscape aesthetics, advertising, advertising panels, posters.

Historial del artículo:

Recibido, 14 de junio de 2017; aceptado, 24 de junio de 2017; disponible en línea, 30 de junio de 2017

* Estudiante de la Universidad Continental.

Correo: 48077056@continental.edu.pe 


\section{INTRODUCCIÓN}

En el Perú, no se percibe la contaminación visual producida por los afiches y paneles publicitarios, por ello, no se ha investigado a fondo las causas culturales, económicas y sociales, menos aún los efectos ambientales, culturales, económicos, sociales y de salud.

En la actualidad la publicidad por medio de afiches y paneles, juega un papel trascendental en el desarrollo e imposición de una marca en el mercado, lo que ha generado una reproducción exorbitante de publicidad exterior, que altera la estética paisajística urbana; sin importar a las empresas que elaboran este tipo de publicidad y a los ciudadanos que arriendan un espacio de su vivienda para colocar los paneles publicitarios.

Si bien es cierto, que en nuestra legislación no se regula de manera expresa la contaminación visual, es preciso mencionar que el OEFA (Organismo de Evaluación y Fiscalización Ambiental), la Defensoría del Pueblo y sobre todo la Municipalidad Provincial de Huancayo, muestran iniciativas para reducir de alguna manera la contaminación visual que existe en la Provincia de Huancayo.

Asimismo, en la actualidad no está comprobado científicamente el daño que producen los afiches y paneles publicitarios tampoco existen indicadores de medición para determinar el grado de contaminación visual, sin embargo se considera indispensable contar con una normatividad para regular la contaminación visual, preservar el paisaje urbano que se encuentra degradado, debido a la saturación e instalación de afiches y paneles publicitarios colocados de manera indiscriminada.

Según Pérez (2000, p. 33): “El concepto de paisaje está referido fundamentalmente a la imagen de un área o territorio determinado, ya sea rural, urbano, acuático, atmosférico, o a una situación combinada entre estos".

En ese sentido, todo paisaje contiene una representación o ilustración de un área o territorio determinado, sea este rural, acuático, atmosférico o combinado, así en la presente investigación tenemos el área urbano.

Ahora bien, Kevin Lynch (citado en Pérez, 2000) nos señala que: La calidad del espacio público juega un papel decisivo en la calidad del paisaje urbano. En el paisaje urbano se destacan elementos arquitectónicos y urbanos que son fundamentales para su valor perceptual e identificación de la memoria urbana, como son las edificaciones y espacios que tienen la función de símbolos, hitos, ejes, nodos, mojones y lugares abiertos de encuentro y recreación como plazas, plazoletas, parques .
De manera que, el paisaje urbano comprende la interpretación visual de la ciudad mediante el cual intervienen diferentes elementos tales como el medio social, medio natural y el medio ambiente en general, siendo importante la calidad del espacio público para una buena calidad del paisaje urbano, asimismo en el paisaje urbano tenemos elementos arquitectónicos y netamente urbanos que en si son importantes para la identificación de una memoria urbana, y en este caso tenemos las edificaciones y espacios que tienen la función de símbolos, lugares abiertos de encuentro y recreación como plazas, plazoletas, parques vivienda unifamiliar o multifamiliar, iglesias, centros administrativos y comerciales, complejos deportivos, puentes todo lo cual son representativos de una ciudad, así también tenemos el amoblamiento urbano tales como los paraderos, señalización, teléfonos públicos.

Sin embargo, en estas áreas urbanas también encontramos afectaciones a ella especialmente de la contaminación visual, la congestión vehicular y la proliferación de basuras e invasiones.

Siendo así, Pérez (2000) en su artículo Paisaje Urbano en Nuestras Ciudades afirma lo siguiente:

Un aspecto importante en la apreciación y calidad del paisaje urbano radica en el tratamiento, presencia y conservación de los espacios y elementos naturales que conforman la estructura verde de la ciudad, como parques públicos, zonas verdes privadas e institucionales de interés público, cuerpos de agua, elementos orográficos y la vegetación presente o ausente en la ciudad y alrededor de ella. El paisaje urbano se puede interpretar como el semblante del medio ambiente y de la calidad habitacional de la ciudad y su espacio público.

Por lo que para una calidad del paisaje urbano de nuestras ciudades es importante el tratamiento y conservación de los espacios y elementos naturales que conforman el área verde de la ciudad, esto es, la conservación de los parques públicos, zonas verdes de interés público, etc.

Sin embargo hoy en día no se está cumpliendo con la conservación de estos espacios públicos, pues:

En general, se encuentran situaciones extremas de deficiencia en el estado de las áreas transitables y del espacio público en diferentes sectores de las ciudades: huecos, contaminación visual por avisos publicitarios, casetas y ventas callejeras, ausencia de arborización, abandono de los separadores y franjas verdes. En áreas administrativas y de representación gubernamental, en áreas de valor histórico y en las zonas de vivienda y comercio suntuario, se registra un alto grado de atención a la conservación de los elementos del paisaje urbano. Invasión del espacio 
público por el denominado sector informal de la población, que debido a la carencia de empleo y vivienda se ve obligado a ocuparlo, especialmente en sectores comerciales, causando perturbación sensorial y de movilidad. La presencia permanente de basuras en muchos sectores de la ciudad, con predominación de los centros comerciales y de los sectores de vivienda popular y marginada. En muchos casos, deterioro, degradación y perturbación sensorial de fuentes por contaminación, que han sido convertidos en alcantarillas abiertas y a los que se arroja continuamente todo tipo de desechos. Congestión vehicular y circulación de automotores en mal estado, por obsolencia y falta de mantenimiento, que en general no cumplen las normas sobre la emisión de residuos contaminantes del aire. (Pérez, 2000, p. 36).

En ese sentido en Huancayo específicamente en las zonas estratégicas de: Los Andes y Ferrocarril; Calle Real y Breña; existe contaminación visual, tales como afiches publicitarios pegados en el exterior de las paredes de las casas, postes, edificios y paneles publicitarios encima de las azoteas de las casas, sobre todo en las zonas específicas.

Actualmente en el Perú existen iniciativas de Municipalidades para reducir la contaminación visual. El proyecto de la Municipalidad Distrital de Comas (2016) "Limpia tu ciudad" tiene la finalidad de solucionar el problema de la publicidad informal, propaganda electoral y contaminación visual, buscando que los partidos políticos y alianzas, el sector no gubernamental, el sector público, municipios, gobiernos regionales y comunidades se concienticen y opten por esta iniciativa; asimismo otorga una solución en tres pasos: primero, el cumplimiento de la legislación a fin de que los candidatos observen la prescripción del artículo 193ํ de la Ley Orgánica de Elecciones que estipula que el borrado o retiro de la propaganda electoral se realice en un plazo no mayor de 60 días después de culminados los comicios; segundo, mayor compromiso para combatir los efectos del cambio climático buscando que todos los candidatos, trasladen su propaganda electoral, sus paneles, afiches y trozos de madera a puntos de acopio para un correcto tratamiento, demostrando así su compromiso con el medio ambiente; tercero, consumo responsable, un equipo selecto transforma los materiales reciclados, en materia prima para fabricar muebles, juguetes de madera, cartucheras, monederos y demás productos reciclados de consumo; con esta iniciativa se busca reducir la contaminación, asimismo busca generar puestos de trabajo, fortalecer la economía y empleo verde cumpliendo lo más importante: cuidar el planeta.

Por otro lado, a pesar de que se sabe que nunca se logrará erradicar totalmente la contaminación visual, se esboza una alternativa de solución, permitir los paneles, pero estos deben de generar beneficios para la población, la página web que publica innovaciones científicas Ecolnventos green technology (2014) incluyó el reporte de "Un panel publicitario que produce agua potable del aire" si bien es cierto el panel promocionaba el proceso de admisión de la Universidad de Ingeniería \& Tecnología (UTEC), y que a su vez generó agua potable beneficiando a la población. Iniciativa que podría ser replicada en otros ámbitos urbanos.

\section{MATERIAL Y MÉTODOS}

Esta investigación se realizó en la ciudad de Huancayo (departamento de Junín), que se encuentra situada sobre los 3271 m s.n.m., en pleno Valle del Mantaro, en la margen izquierda del río del mismo nombre; circunscribiéndose a las intersecciones formadas por las siguientes vías principales:

- Avenida Giráldez, Breña y Calle Real.

- Avenida Huancavelica y Breña.

- Avenida Ferrocarril y Los Andes.

En las vías principales elegidas se percibe en gran cantidad y diversidad avisos informativos publicitarios luminosos, paneles publicitarios y afiches los cuales generan molestias a los ciudadanos.

El tipo de investigación fue básica, ya que, con los resultados hallados se contribuyó al enriquecimiento del conocimiento respecto a los impactos generados por la contaminación visual en nuestro país. La investigación considero el nivel descriptivo, pretendiendo describir los impactos sociales y ambientales que genera la contaminación visual.

El diseño de la investigación es no experimental transversal descriptivo, con enfoque metodológico cuantitativo.

Para efectos del trabajo, una fuente de información comprendió la aplicación de un cuestionario y entrevistas a una muestra de 80 personas seleccionadas del género masculino y femenino, cuya edad superó los 18 años.

Se realizó trabajo de campo aplicando la observación directa en varias oportunidades, se aplicó un cuestionario estructurado, entrevistas no estructuradas y semi estructuradas así como se generaron archivos fotográficos y de videos. Además, se analizó la normatividad aplicable al presente caso. 


\section{RESULTADOS}

El objetivo del cuestionario fue recolectar información de los actores involucrados en esta problemática, como taxistas, transeúntes y comerciantes de las zonas encuestadas; el $70 \%$ no tenían conocimiento de lo que es contaminación visual, por otro lado el 80 \% señaló que tanto los paneles luminosos como afiches en exceso les genero irritación a la vista, y el 20 \% estrés, finalmente el $90 \%$ refirió que nunca realizo alguna denuncia o queja, pero el $60 \%$ de los ciudadanos no conocían como reaccionar frente a esta problemática.

\section{La normatividad}

Frente a esta problemática las entidades gubernamentales competentes para regularla son: La Municipalidad Provincia de Huancayo, la Defensoría del Pueblo, el Organismo de Evaluación y Fiscalización Ambiental, así como el Ministerio de Cultura. La responsabilidad ambiental de las entidades antes mencionadas y de los infractores se enmarca en los ámbitos administrativo, civil o penal conforme corresponda.

En ese sentido, de conformidad a lo dispuesto en el artículo $192^{\circ}$ inciso 7 de la Constitución Política del Perú (2016), los gobiernos regionales son competentes para promover y regular actividades y/o servicios en materia de salud y medio ambiente entre otros, conforme a ley. En ese orden de ideas conforme a lo señalado por el sub numeral 1.4.4. del artículo 79 de la Ley Orgánica de Municipalidades que, establece que son funciones específicas y exclusivas de las Municipalidades provinciales se encuentran la autorización para la ubicación de anuncios y avisos publicitarios y propaganda política. En ese sentido la Municipalidad Provincial de Huancayo deroga la Ordenanza municipal N $N^{\circ} 308-M P H / C M$ y se aprobó el nuevo Reglamento de Publicidad Exterior Temporal y/o eventual mediante la Ordenanza municipal $\mathrm{N}^{\circ}$ 472-CM/MPH, siendo así en el artículo 2 del mismo nos menciona que el objetivo general es recuperar la estética urbana en lo referente a la exhibición y/o difusión de publicidad exterior eventual a través de normas de orden administrativo que regulen el otorgamiento de las autorizaciones para dichas publicidades y que contribuyan también a recuperar el valor de la zona monumental de Huancayo como una ciudad histórica y tradicional, además se señala como objetivo específico preservar el ornato de la ciudad, evitando la contaminación visual orientado a un mejor ordenamiento urbano, en otro lado, en el artículo 8 nos señala el reglamento que, no se otorgara autorización municipal cuando los cambios de intensidad de luz de magnitud que moleste a la vecindad, también cuando afecte a la vista o atención de los conductores de vehículos y peatones por la intensidad de luz, dirección de sus rayos o colores, por perjudicar la visibilidad de las señales de tránsito, etc., De manera que podemos decir que este reglamento busca proteger a las personas y a la estética urbana de la ciudad, sin embargo en la realidad no se estaría cumpliendo con la misma. Ahora bien, el artículo 9 de este reglamente también nos señala que se podrá instalar toda forma de publicidad exterior temporal en zonas monumentales, esto es, en inmuebles de valor históricos-artístico de la época republicana y contemporánea que integrados conforman espacios - ambientes urbanos (plazas, plazuelas, calles) por poseer valor urbanístico, documental histórico, razón por la cual deberá ser autorizada previamente por el Ministerio de Cultura y luego ya por la Municipalidad Provincial de Huancayo, teniendo como periodo de autorización hasta por 01 año. De modo que se puede autorizar la exhibición de afiches y paneles publicitarios en zonas monumentales y hasta por un año, claro que cumpliendo ciertos parámetros que no afecten los monumentos históricos, ¿̇pero en la realidad se estará cumpliendo?, ¿̇ónde está la actuación del Ministerio de la Cultura en este caso?. Asimismo la ordenanza establece que no se permitirá más de 01 elemento publicitario de carácter temporal o eventual (panel o valla publicitaria) en una sola estructura metálica con la finalidad de evitar la contaminación visual, sin embargo para evitar la contaminación visual żcuántos paneles publicitarios deberán exhibirse en una misma intersección de una avenida o calle?

Ahora bien tenemos a La Ley Orgánica de Elecciones, Ley № 26859 que, en su artículo 193ํ nos señala que: "Concluidos los comicios electorales, todos los partidos políticos, listas independientes y alianzas en un plazo de 60 (sesenta) días proceden a retirar o borrar su propaganda electoral. En el caso contrario, se hacen acreedores a la multa que establezcan las autoridades correspondientes". Siendo esta normativa de importante cumplimiento en la sociedad.

\section{Responsabilidad de cada actor involucrado}

1. La responsabilidad civil ambiental, se da cuando aquel que por dolo o culpa causa un daño a otro está obligado a indemnizarlo, encontrando su amparo legal en el artículo 1968 del Código Civil (1984). Por lo que toda persona que cause un daño ambiental puede ser pasible de una demanda por responsabilidad extracontractual.

2. La responsabilidad penal ambiental, se da cuando el que contraviniendo las disposiciones de la autoridad competente, altera el ambiente natural o el paisaje urbano o rural será reprimido con pena privativa de la libertad. Encontrando amparo en el artículo $313^{\circ}$ del Código Penal. Asimismo, el artículo $314^{\circ}$ del mismo, nos refiere que el funcionario público que sin observar leyes, 
reglamentos, estándares ambientales vigentes, por haber faltado gravemente a sus obligaciones funcionales, autoriza el otorgamiento, renovación o cancelación de autorización, licencia, concesión, permiso $\mathrm{u}$ otro derecho habilitante en favor de la obra o actividad será reprimido con pena privativa de libertad e inhabilitación, igualmente para el servidor público que incumpla sus funciones.

3. Responsabilidad administrativa ambiental, en este caso, el incumplimiento a la Ordenanza municipal $N^{\circ}$ 472-CM/MPH que aprobó el nuevo Reglamento de Publicidad Exterior Temporal y/o eventual conlleva a una sanción administrativa por parte de la Municipalidad Provincial de Huancayo.

\section{DISCUSIÓN}

La percepción de la contaminación visual de paneles publicitarios y afiches por parte de los actores involucrados que comprendieron los taxistas, transeúntes y comerciantes de las zonas específicas de: la Av. Giráldez y Breña; Breña y calle Real; Breña y Huancavelica, finalmente de la Av. Los Andes y Ferrocarril (esquina con Open Plaza) de la Provincia y distrito de Huancayo se caracterizaron porque la mayoría no tiene conocimiento de que es la contaminación visual; sin embargo, lo asociaron a elementos u objetos que irritan la vista, distorsión del paisaje urbano de la ciudad, estrés, ansiedad sobre todo al apreciar el excesivo uso de paneles luminosos y afiches publicitarios; asimismo estas descripciones son también definidas por Pérez (2000) quien señaló: "En general, se encuentran situaciones extremas de deficiencia en el estado de las áreas transitables y del espacio público en diferentes sectores de las ciudades: huecos, contaminación visual por avisos publicitarios, casetas y ventas callejeras, ausencia de arborización, abandono de los separadores y franjas verdes". Por otro lado, la mayoría de los encuestados refirieron que no tomaron acciones pertinentes tales como denuncias, quejas contra la contaminación visual en Huancayo, entendiéndose que se debe al desconocimiento sobre lo que es realmente esta problemática, sus causas y efectos, lo cual no es de extrañar al ser un tipo de contaminación ambiental tan nuevo, conforme así también es reportada por Ortiz y Murillo (2006).

Ahora bien, se tiene que La Defensoría del Pueblo de Huancayo según Correo (2014) habría tomado medidas respeto a las propagandas políticas retirando y quemando más de 5000.00 propagandas electorales, así como el Titular del Jurado Electoral Especial de Elecciones advirtió denunciar penalmente la reincidencia de candidatos de colocar afiches de propagandas electorales; por lo que estas iniciativas colaboran al control y fiscalización de la contaminación visual en la ciudad de Huancayo respecto a las propagandas electorales pero aún falta incentivar a realizar acciones contra el uso excesivo de paneles luminosos y afiches publicitarios de manera general; de igual modo a pesar que el Organismo de Fiscalización Ambiental (2016) capacitó y brindó talleres a los funcionarios de los gobiernos locales sobre las obligaciones ambientales no se habría tomado en cuenta en dichos eventos específicamente el tema de la contaminación visual restándole así la importancia debida.

En cuanto a los mecanismos de defensa contra la contaminación visual no se ha evidenciado una preocupación por parte del gobierno regional, pues no se está dando cumplimiento a la Ordenanza Municipal N ${ }^{\circ} 472-\mathrm{CM} / \mathrm{MPH}$ (2018) que, en su artículo $15^{\circ}$ nos menciona que la Gerencia de Desarrollo Urbano y Ambiental de la Municipalidad Provincial de Huancayo es el órgano competente para autorizar la instalación y/o exhibición de anuncios y todo elemento de publicidad exterior de carácter temporal-eventual, así como resolver en primera instancia los recursos administrativos relacionados con la publicidad exterior de carácter temporal-eventual y proponer normas complementarias para el mejor cumplimiento del reglamento, asimismo en el caso que se instaleexhiba y/o difunda elementos de publicidad exterior $\sin$ la respectiva autorización municipal, la unidad competente tendrá todo el derecho de aplicar las sanciones administrativas de acuerdo al trámite del Cuadro único de Infracciones y Sanciones. De manera que, es competencia de la Municipalidad Provincial de Huancayo de regular y sancionar a toda persona natural o jurídica que utilice los anuncios publicitarios a través de paneles o afiches para promocionar algo de manera indiscriminada, así como a las personas que alquilan sus bienes inmuebles para la instalación - exhibición de dichos elementos publicitarios sancionarlos como responsables solidarios, puesto que no solo el uso indiscriminado y excesivo de estos anuncios afectan la estética urbana, sino que afectan a la salud física, psíquica y emocional de las personas. De igual modo, ante el diario RPP noticias (2013), la Gerente de Desarrollo Urbano y Ambiental de la Municipalidad de Huancayo sancionó a un mínimo de 25 personas por pegar afiches y propagandas en las paredes y postes de esta ciudad con una multa de hasta 1,850.00 Soles, asimismo dijo que estas cifras son mínimas ya que no hay personal que supervise en las calles e intervenga a aquellos que pegan estos afiches indiscriminadamente, razón por la cual la contaminación visual es cada día mayor. Siendo así, además de aplicar las multas, se tiene que destinar un conjunto de efectivos policiales en las calles de Huancayo para fiscalizar y dar cabal cumplimiento a la ordenanza municipal. Asimismo, ante el Diario Correo (2017) el catedrático de la Universidad Continental, Arquitecto César Moncloa Guardia manifestó que estos anuncios publicitarios excesivos en las azoteas, 
paredes de las casas, en los postes y señales de tránsito convierten a los ciudadanos en consumidores, ocasionando así en una forma de contaminación visual que, por lo general mantiene distraída a la persona, causa ansiedad y promueve la necesidad de consumo convirtiendo a las calles en vitrinas. Asimismo, el gerente de Desarrollo Urbano de la Municipalidad Provincial de Huancayo, Julio Balvín Méndez refirió a este diario que dichos anuncios están por todo el centro, pero en mayor medida en la Av. Ferrocarril, además que no respetan la distancia de 100 metros lineales, ni cuentan la mayoría con autorización. Por lo que no podemos permitir que nuestras calles continúen siendo un mostrador de publicidades, siendo necesario ponerles límites para que así no afecten la salud física y mental de nuestros pobladores.

Por otro lado, tampoco existen en nuestra ciudad demandas civiles, penales o administrativas que se hayan iniciado ante la Corte Superior de Justicia de Junín o ante el Ministerio Público de Junín, no obstante, al consultar ante la Fiscalía especializada en materia ambiental, si es que se había recibido o tomado conocimiento de alguna denuncia por contaminación visual, nos respondieron que no tomaron conocimiento de alguno, puesto que no existe en la contaminación visual daño ambiental. Sin embargo, Peña (2010) nos indica que: "los delitos ambientales son un tipo penal mixto, porque se configuran dos posibilidades:

1. Puede causar un daño o alteración al medio ambiente o algunos de sus componentes, estamos hablando que la conducta del agente puede causar un riesgo potencial, daño o alteración al ambiente o sus componentes.

2. Se verifique un daño efectivo, es decir, que se ha acreditado que la conducta del agente ha ocasionado un riesgo al ambiente o uno de sus componentes. Para ello deberá comprobarse el daño, cuestión en la que la autoridad administrativa juega un rol trascendental. (pg. 131).

Siendo así en los delitos ambientales hablamos de un daño o alteración al medio ambiente o algunos de sus componentes, en el presente caso, tenemos un daño o alteración a la estética urbana de la ciudad de manera evidente; además un daño a la salud física, psíquica y emocional de las personas, esto último sin embargo es difícil de comprobar por lo que se necesita de la ayuda de la ciencia para contrastar los mismos, ya que no existen indicadores de medición de la contaminación visual, pero consideramos que es importante que se investigue y aplique, para controlar la contaminación visual, aunque la autoridad administrativa también cumple un rol trascendental, así conforme Derecho y Sociedad-Asociación Civil (2010) la conducta antijurídica va estar determinada por el incumplimiento en sede administrativa de las normas ambientales, en este caso, de la ordenanza municipal de la Provincia de Huancayo acerca de las autorizaciones de publicidad exterior, de manera que la gerencia a cargo deberá de sancionar con firmeza los actos de las personas jurídicas y/o personas naturales que contravengan la ordenanza para que así el Ministerio Público como órgano persecutor del delito sancione como delito ambiental estas conductas antijurídicas, ya que el fin supremo de la sociedad y del Estado es la defensa de la persona humana y el respeto de su dignidad artículo 1 de la Constitución Política del Perú.

Finalmente, respecto a la legislación Argentina DIARIODPI (2016) nos señala que en el caso de los elementos publicitarios se prohíbe su establecimiento en estatuas, monumentos y otras expresiones artísticas, templos, edificios públicos; plazas, parques, terrenos públicos, en balcones, quioscos de venta de diarios y revistas, los que desfiguren el diseño de la fachada ocultando balcones y ventanas, etc. Asimismo en dicho país, la preservación y restauración del patrimonio natural, urbanístico, arquitectónico y de la calidad visual y sonora integra ese bien jurídico que compromete, como deber, a los órganos del Estado, incluso a los judiciales, según la tarea propia de cada uno de los ellos, siendo necesario contar con controles estrictos para proteger las características propias de la comunidad, la calidad de vida y la economía local imponiendo la obligación de que los carteles sean ubicados solamente en lugares limitados para tal fin, teniendo como uno de sus fines el turismo por sus rasgos característicos, paisajes y elementos arquitectónicos y no quedar invadida de carteles publicitarios.

En conclusión, si bien es cierto en el Perú no se regula el tema de "Contaminación visual" propiamente dicha, pero las entidades gubernamentales como el Organismo de Evaluación y Fiscalización Ambiental (OEFA), Defensoría del Pueblo y la Municipalidad Provincial de Huancayo, deben tomar mayores iniciativas para reducir de alguna manera la contaminación visual que existe en la ciudad de Huancayo, fiscalizando y a la vez sancionando drásticamente todo incumplimiento a las normas, por otro lado como aun no existen estudios respecto a las consecuencias que nos puede causar, pasamos por alto en muchas ocasiones, o en otras, desconocemos completamente de lo que se trata y la forma en la que nos afecta de acuerdo a la investigación realizada por ello se debe tener en cuenta que existen dos factores característicos de la contaminación visual, como el desorden y el abuso (o exceso). Es necesario que la comunidad permita el conocimiento de la importancia de plantear medidas para combatir y prevenir la contaminación visual. Con la eliminación parcial nos referimos a restringir los carteles en ciertas zonas. Tomando como precedentes normativas internacionales como regularon y enfrentaron este tipo de problemas. Asimismo presentamos el proyecto 
ojivisual mediante el cual se tiene como objetivos hacer conocer a los ciudadanos de la existencia de la contaminación visual, en primer lugar realizar una campaña, luego un incentivo al ciudadano, para que no permita el acceso de paneles publicitarios luminosos por las calles o en su vivienda, sino cuenta con una autorización de la Municipalidad.

\section{REFERENCIAS BIBLIOGRÁFICAS}

Correo, D. (30 de agosto de 2014). Queman propaganda electoral que infringia norma. Diario Correo.

DIARIODPI (2016). Diario Ambiental Nro. 129. "La contaminación visual en la Ciudad Autónoma de Buenos Aires. Un repaso de su normativa y jurisprudencia". Recuperadode: https://dpicuantico. com/sitio/wp-content/uploads/2016/09/DoctrinaAmbiental-Nro-129-29.09-1.pdf

Ecolnventos green technology, (3 de Febrero 2014). Un panel publicitario que produce agua potable del aire. recuperado de https://ecoinventos.com/ un-panel-publicitario-que-produce-agua-potabledel-aire/

Huancayo latitud y longitud. Recuperado de: https:// www.distanciasentre.com/pe/huancayo-latitudlongitud-huancayo-latitud-huancayo-longitud/ LatitudLongitudHistoria/280341.aspx

Mendoza, R. (26 de abril del 2013). Huancayo. Municipalidad sanciono a 25 personas por pegar afiches. RPP noticias. Recuperado de: http://rpp. pe/peru/actualidad/huancayo-municipalidadsanciono-a-25-personas-por-pegar-afichesnoticia-589253

Ministerio de Justicia y Derechos Humanos (2017). La Constitución Política del Perú. Recuperado en http://spii.minjus.gob.pe/libre/main.asp

Ministerio de Justicia y Derechos Humanos (2017). La Ley General del Ambiente Ley № 28611. Recuperado en http://spii.minjus.gob.pe/libre/ main.asp

Ministerio de Justicia y Derechos Humanos (2017). Ley Marco del Sistema Nacional de Gestión Ambiental Ley № 28245. Recuperado en http://spij.minjus. gob.pe/libre/main.asp
Ministerio de Justicia y Derechos Humanos (2017). La Ley Orgánica de Elecciones, Ley № 26859. Recuperado en http://spij.minjus.gob.pe/libre/ main.asp

Ministerio de Justicia y Derechos Humanos (2017). Código Civil. Recuperado en http://spii.minjus. gob.pe/libre/main.asp

Ministerio de Justicia y Derechos Humanos (2017). Código Penal. Recuperado en http://spij.minjus. gob.pe/libre/main.asp

Municipalidad Distrital de Comas. (2016).Proyecto Limpia tu ciudad, recuperado de: http://www. limpiatuciudad.com/unete-a-nosotros/

Municipalidad Provincial de Huancayo (2018). Ordenanza Municipal $\mathrm{N}^{\circ}$ 472- CM/ MPH. Recuperado de: http://www.munihuancayo.gob. pe/portal/upload/documentos/2012/ordenanza/ OM12472.pdf

Organismo de Evaluación y Fiscalización Ambiental, "El OEFA define sus acciones de fiscalización ambiental en Junín", publicado en Junin, el 14 de Julio de 2016 disponible en http://www.oefa.gob. $\mathrm{pe} /$ noticias-institucionales/el-oefa-difunde-susacciones-de-fiscalizacion-ambiental-en-junin

Ortiz, A. y Murillo, S. (2006). Contaminación visual: análisis del casco urbano de San José. (Tesis de Maestría). Universidad de Costa Rica. San José.

Peña, A., (2010). Los Delitos contra el Medio Ambiente. Lima-Perú. Rodhas SAC.

Pérez, E. (2000). Paisaje urbano en nuestras ciudades. Bitácora Urbano Territorial, 1(4), 33-37.

Ramos, C. (24 de abril de 2017). Paneles y anuncios en exceso aturden a los peatones y conductores. Correo Huancayo. Recuperado de: https:// diariocorreo.pe/edicion/huancayo/paneles-yanuncios-en-exceso-aturden-a-los-peatones-yconductores-745556/

Torres, R. (2010). Los Delitos Ambientales y la Actuación Procesal de los Fiscales Especializados en Materia Ambiental. Sociedad y Derecho. Revista (N³5). Pg. 140-145. 